\title{
Surf's Up: Work, Life, Balance and Brand in a New Age Capitalist Organization
}

\begin{abstract}
This paper reframes the notion of work/life balance through analysis of branding and the immaterial labour process in a 'new age capitalist' organization. The company does not manufacture material products; rather, value is produced through branding imported goods to promote 'alternative' ways of living. This is achieved through incorporation of leisure activities and lifestyles of key employees, effectively putting their 'lives' to 'work' in the creation of value for the company. For employees, therefore, much work actually takes place notionally outside or on the margins of their formally employed space and time. We argue that this qualitatively transforms the conceptions of, and relations between, work and life that underpin the concept of work/life balance. We conclude by exploring the tensions generated by organizational incorporation of employee autonomy in the pursuit of aspirational branding.
\end{abstract}

\section{KEY WORDS}

authenticity / branding / identity / New Age capitalism / work/life balance 


\section{Introduction}

It is a commonplace that business organizations should take heed of the work/life balance of employees. Policy think-tanks, government reports, trade unions, employer associations and managerial associations draw attention to the need to take employees' extramural activities and commitments seriously (e.g. Clutterbuck, 2003; Nadeem and Metcalf, 2007). This interest has been driven by various factors, including globalization, new technology and, in some countries, aging populations and declining fertility rates (Gregory and Milner, 2009). The last two dynamics have generated commentary that focuses on 'family friendly' employment policies designed to balance effective social reproduction with efficient production.

As well as leading to disproportionate attention on working mothers (Edwards and Wajcman, 2005; Lewis, Gambles and Rapoport, 2007; Gregory and Milner, 2009), this focus on 'life as family' has neglected other 'life' activities such as leisure and recreation, in part because child-rearing is legitimated as a productive activity (Ransome, 2007). Many analyses of work/life balance maintain a quantitative understanding of 'balance' by advising on the balance of working time against the temporal demands of home and childcare. Where there is acknowledgement of the ways in which work encroaches upon life, for example through teleworking and information and communication technologies (ICT), the dominant assumption is that 'work' and 'life' are two discrete spheres. This in turn leads to an emphasis on whether people are really working longer hours, or more intensively, and whether work is taking over life (Warhurst et al., 2008). Much less attention has been given to transformations in nature of work and qualitative changes to the boundary between work and life. Notable exceptions are Lewis (2003) and Fincham (2008), who both work towards re-conceptualising the work/life relationship.

In this paper we draw on these recent reframings of work/life balance and introduce a literature that, so far, has not been connected to the idea, but which offers a fruitful qualitative analysis of the changing nature of work and life. The autonomist Marxist approach to social theory addresses the recomposition of capital and labour in late capitalism (Dyer-Witheford, 1999; Hardt and Negri, 2000; Lazzarato, 1997). A key concern is that 'work' - understood as value producing activity - is increasingly concerned with communication and social reproduction, and often takes place outside 
formally designated employment time/space, leading to the idea that we live and work in a 'social factory' (Dyer-Witheford, 1999; Hardt and Negri, 1994; Poulter and Land, 2008). Applying this to an analysis of the political economy of brands, Arvidsson (2006) notes that branded products are consumed because of the meanings associated with them. Because meaning is realised and reproduced through the act of consumption, consumers are effectively co-producing the value of the brand. As such, consumption, which would traditionally be thought of as recreation or leisure, is qualitatively transformed into a variety of work.

However while autonomist perspectives draw attention to the possibility of qualitative transformations in the work/life boundary, little empirical attention has been given to the effects of such changes on the labour process of employees inside brand oriented organizations. This paper brings these two perspectives together to analyse Ethico (a pseudonym, as are all our respondents' personal names), an ethically oriented, branddriven clothing company that successfully combines 'New Age' discourses of spirituality and environmentalism with the promotion of counter-cultural sports such as surfing, skating, BMXing and canoeing, to produce a recognisable brand in a highly competitive industry. We explore the ways in which Ethico employees' leisure activities are mobilised as part of the brand narrative. By incorporating the cultural identities and values of some employees ${ }^{1}$ into the brand, life-interests and leisure activities become productive of brand value, thus qualitatively reconfiguring the relations between 'work' and 'life'. This analysis contributes to our understanding of relations between work and leisure (Lewis, 2003; Fincham 2008), or recreation (Ransome, 2009), by examining the political-economic role of those activities in producing exchange value through the symbolic, or immaterial, labour of brand management based on employees' recreational activities.

The structure of the paper is as follows. First we review literature on work/life balance to explore how 'recreation' and 'leisure' have come to challenge dominant conceptions of work/life balance relating to family life and childcare. We suggest that an approach to work/life balance that focuses on quantitative understandings of the relationship between work and life misses ways in which both spheres of activity are transformed by changes in the capitalist production of value. To understand these changes, we introduce autonomist Marxist writings on value and work, and focus on Arvidsson's (2006) study of branding and consumption as a form of labour. This sensitises us to the qualitative 
dimensions of the boundary between work and life and how this boundary may be transgressed or challenged by branding. We then introduce the Ethico case study with a brief discussion of methodology before the main analysis, which focuses on three examples of how work, life, and the boundary between them, were articulated by employees at Ethico.

\section{Work, Life, Balance}

Since at least the 1960s, academics, personnel managers and policy makers have been interested in managing the relationship between work and family life (Lewis and Cooper, 2005). Following traditional sex/gender divisions of labour, these discourses implicitly or explicitly assume that the subject of the work/life balancing act was a 'generic female parent' (Smithson and Stokoe, 2005), whose primary responsibilities outside of work were domestic and reproductive labour (Ransome, 2007; McKie et al., 2002). This focus remains at the heart of the discourse, driven now by declining fertility rates and an aging population (Gregory and Milner, 2009). With more women in paid employment, work/life balance has been adapted to create space for reproductive labour and family care work - crucial economic concerns for any government.

Two other factors driving the work/life balance discourse are globalization and technological change (Gregory and Milner, 2009). Globalization, it is claimed, brings in its wake increased competition among businesses, with a concomitant rise in working hours and intensity. Although evidence of an absolute increase in working hours is contestable (Warhurst et al., 2008), it would appear that for managers at least long hours are a norm, particularly in industries with a culture of presenteeism (Watts, 2009). More generally, weakened trade unions, deregulation, reorganization, efficiency drives and the emergence of the $24 / 7$ workplace combine with technological innovation to increase the intensity, if not the absolute hours, of work, raising further concerns over the achievement of balance (Lewis et al., 2007). Developments in ICT, particularly mobile communications, also contribute to the erosion of the work/life boundary, allowing working practices to spill over into what would previously have been private spaces and times, such as family holidays, whilst simultaneously facilitating the kinds of flexible working arrangements that are said to support an effective work/life balance (Wajcman, 2008; Wajcman et al., 2008). 
These approaches to work/life balance share a tendency to equate 'work' with paid employment and 'life' with domestic labour and care work. The main concern is then how to 'balance' these relatively discrete quantities of work and life. More recently, however, this approach has been the subject of criticism for its narrow focus and neglect of non-productive forms of 'labour'. Ransome (2007) notes that only $22 \%$ of UK households contain dependent children, and suggests that taking childcare as the model for 'life' risks generalizing from a small minority to a much larger population whose concerns, and lives, are quite different. Ransome offers a third category of activity, 'recreational labour', to set alongside paid employment and unpaid care work. This distinction is based on the argument that paid employment and unpaid care are primarily concerned with extrinsic utility or practical outcomes, both essentially imposed by the objective situation in which people find themselves (the need to earn money, the need to maintain oneself and one's family). Recreational labour, in contrast, achieves utility through more intrinsic, personal satisfaction and is motivated by subjective desires (Ransome, 2007). This form of labour might include community activities, care of self, leisure, and pleasure. The inclusion of this third category within the notion of work/life balance extends its relevance to the $78 \%$ of UK households that do not include dependent children, and speaks more directly to the full range of concerns that members of all households share when seeking to balance 'work' and 'life'.

Ransome's concept of recreational labour allows us to better explore the boundary between work and life, and how these spheres are intertwined and interdependent. Just as domestic, reproductive labour is inseparable from economically productive paid employment (Glucksmann, 2000; Dyer-Witheford, 1999; Dalla Costa and James, 1975), so recreational labour is articulated alongside both paid work and unpaid care work. Often these activities overlap with what goes on in the realm of 'work' (socializing with work colleagues), and with necessary non-market activities in 'life' (playing with children). To this we can add a substantial realm of activity taken up with various kinds of community organizing including voluntary, political and trade union work (Ransome, 2007). Whilst these latter activities may take place in the home or the workplace, they are not objectively determined by domestic or contractual demands. Whilst Ransome recognises that this boundary is permeable, in relation to the spatial and temporal location of the activities, he focuses on the distinct, subjective and intrinsic, motivations 
that drive recreational labour as opposed to the objective, extrinsic factors driving the other activities.

Ransome's approach to non-productive aspects of 'life' is similar to that found in Lewis' (2003) analysis of the relationship between work and leisure for chartered accountants. Lewis also analyses leisure in terms of motivation, defining it as

'non-obligated time... activities that are freely chosen... and activities associated with a sense of enjoyment.' (Lewis, 2003: 345).

This enables Lewis to explain the fact that those most able to determine their own working patterns and hours - accredited professionals - often choose to work longer hours rather than increase non-work activities. Fincham's (2008) account of bicycle messengers provides a further refinement of this model, arguing that the work/life distinction is inapplicable for some occupational groups. For bicycle messengers, the high degree of subcultural affiliation and coherence of identity across work and nonwork contexts generate a sense of community within which the notion of balancing work and life carries no meaning, as they are thoroughly integrated and practically inseparable.

Whilst these perspectives on work/life balance are more nuanced than most, with the exception of Fincham (2008) they share the assumption that that traffic across the boundary is largely one-way: work increasingly dominates life. Discussions of long hours, work intensification, burnout, parental leave and flexible working patterns, are all concerned with defending life against encroachment from work. Even when the boundary between work and life is defined in terms of motivation and enjoyment, rather than space and time, the dominant concerns remain how work is taking over leisure and how such choices are constrained by occupational cultural norms and career paths (Lewis, 2003). It is our argument in this paper, however, building on Fincham's (2008) analysis, that it is precisely in respect of motivation and utility that new forms of work are breaking down the distinction between work and life in both directions. To understand these changes we turn to a broader analysis of the changing nature of work.

\section{Immaterial labour, value and symbolic capital}

To better understand changes in the relationship between work and life we need to analyse not only how the quantitative balance between them has shifted, but also how 
the qualitative nature of both has been transformed by changes in the production and circulation of economic value. In a social theoretical tradition going back to the 1970s, autonomist Marxists have analysed transformations in the capitalist labour process, paying particular attention to the changing locus of value production in late-capitalism (Dyer-Witheford, 1999; Hardt and Negri, 1994, 2000; Lazzarato, 1997; Wright, 2002).

For this strand of theory, value production has moved outside the workplace to subsume the whole of society and life itself. Within traditional Marxist analyses value was produced during discrete hours of work (Böhm \& Land, 2009), with the socially necessary amount of time required to produce a commodity determining its value (Marx, 1976). Autonomists, however, suggest that in late capitalist economies the manufacture of material commodities is not the primary source of value creation. Outsourcing material production to lower-wage economies enables managers to focus on 'core' activities such as marketing and brand management (Quinn, 1992; Klein, 2000). Production and consumption are oriented towards the meanings associated with a product, constructing signifying complexes of which the material commodity is just the bearer.

This labour - the immaterial production of meaning and signification - is distinct from material industrial labour in two senses. First, value-adding work takes the form of communication; for example, interactive service and care work, post-Fordist manufacturing, or the knowledge work of 'symbolic analysts' (Hardt and Negri, 2000). Second the use value of commodities, their meaning and ability to signify, is essentially indeterminate and dependent upon reception. This breaks down the possibility of a clear separation between consumption and production. From this perspective, the meaning, and therefore value, of a brand is dependent upon its co-production through the act of consumption. The precariousness of this reception, and therefore of value production, is evinced by resistance practices like culture jamming, hacking and ad-busting (Carducci, 2006; Harold, 2004).

From this autonomist perspective, the relationship between work and life has been thoroughly eroded by the recomposition of capital. Arvidsson (2006: 30) summarises this well:

'Capital (in the form of propertied symbols, and signifying complexes: advertising, brands, television series, music and other forms of content) is 
socialized to the extent of it becoming part of the very environment, the biopolitical context in which life is lived. The other side to this equation is that life comes to evolve entirely within capital, that there is no longer any outside.' One consequence of this 'real subsumption' (Negri, 1991) is the removal of the production of economic value from the direct control of managers. Direct supervision of value productive labour processes is impossible because the production of economic value - especially in the form of brand equity - is dependent upon autonomous processes of social reproduction and communication taking place 'outside' corporations. On the other hand, all acts of social production, even life itself, become potentially valueproductive forms of labour.

Arvidsson's (2006) work reframes the work/life boundary through political-economic analysis to suggest that life is work and work is life. As such his analysis can be read alongside studies of the work/life balance to draw attention to forms of value producing labour, or work, outside the formal employment contract. However, whilst this is theoretically significant, Arvidsson's analysis does not give sustained empirical attention to how these changes shape the labour process within brand based organizations (cf. Thompson, 2005). The rest of this paper combines Arvidsson's analysis of brand value production with our critique of the work/life balance literature, through an empirical analysis of an 'ethical' brand based clothing company, to explore how the production of value reconfigures certain employees' work/life interactions.

\section{Research methods}

Ethico is a small clothing company founded in 1995. It directly employs around 25 people in the UK, mainly in sales, marketing, and warehousing. The company's brand identity is founded on 'authenticity' and ethical trading. According to the founders, the typical customer is an urban thirty-something professional concerned about environmental degradation. Although the company's clothes can be found in a small number of specialist outlets, at the time of the research most business was through direct sales to customers via internet and catalogue. The company charges a premium for clothes and accessories on the basis of both brand and ethical sourcing of organic, natural or recycled materials. As part of its stance Ethico promotes the reduction of 
consumption, arguing that customers should buy more expensive but higher quality products that last longer.

Size is also significant in Ethico's brand identity. Promotional materials draw heavily on family and community metaphors. Employees' difficulties in balancing leisure pursuits, their desire to work hard for Ethico, and the need to make the world a better place are also frequently referred to. The company self-defines as a producer of sports clothing targeted at surfers, mountain-bikers, BMXers and skateboarders. Promotional materials note the challenges in balancing the promotion of ethical and environmental principles with profit. This tension is significant for Ethico and other similar organizations attempting to trade in a 'non-corporate' way; promotional materials and internet-based customer discussions often note the fine line between offering a vision of an alternative way of life and the potential for 'inauthenticity' and 'selling out'.

Ethico is a prime example of a brand based organization located within 'New Age capitalism' (Lau, 2000). Although Ethico may be interpreted as an 'atypical case' of work/life balance (Seymour, 2007) when considered within the broad category of contemporary workplaces, within the emerging institutional field of New Age economic activity - sometimes referred to as the 'holistic milieu' (Heelas and Woodhead, 2005), founded on a set of quasi-spiritual principles about living, working and doing business (Taylor, forthcoming) - it appears more modal. Ethico and other organizations such as Innocent valorise physical and spiritual wellbeing, holism, environmental awareness, activism, and social change through reduced consumption, claiming to incorporate those values into their working practices and brand.

Despite, or perhaps because of, their highly visible and valuable public profiles, empirical analyses of organizations such as Ethico are rare. This may be a result of difficulties in negotiating access, reflecting a desire to maintain or protect valuable brand identity. We made initial contact with the press/media officer at Ethico in October 2006, then conducted a 6 month-long series of email and phone conversations before finally being granted permission to visit the organization in April 2007 to collect data. Even then we were only able to visit for two days. We observed work and conducted 11 formal semistructured interviews; we also took notes during informal conversations with staff, photographed workspaces, and recorded manifestations of the organization's culture (e.g. 
artefacts, 'non-work' spaces such as the kitchen, employee clothes, workspace layout and decor, and music) in our fieldnotes. In addition we analysed eight quarterly catalogues produced by the company, each around 70 pages long; t-shirt logos and slogans; public internet discussion board text concerned with the company; employee blogs on the Ethico website; and email circulars sent by the company to customers.

With such a diverse data set of naturally occurring and researcher-prompted texts and images, we chose to construct an account of the organization drawing on the tradition of the qualitative case study. We work with all three variations of case study as identified by Stake (2005), intrinsic, instrumental, and collective. Our initial intrinsic interest in the company was based on the collective significance of its New Age capitalist combination of economic value and ethical values. However early in the data collection process, we identified work/life balance as empirically significant, and developed it into an analytical theme. In this respect we also treat Ethico as an instrumental case to illustrate the changing nature of the interplay between work and life, by examining the impact of adherence to brand values on those employed to work for the organization. Our method thus aligns with our problematic (Flyvbjerg, 2006) to provide an exemplar of the lived experience of work in this emergent economic sector.

In our analysis, we present two parallel accounts of Ethico. First, we suggest that there is a clear and established process of constructing a brand identity that both draws on, and contributes to, customer identity: a continuous circuit, as Hall (1980) puts it, of production, distribution, and reception/reproduction. As brand theorists, notably Arvidsson (2006), suggest, the combination of consumer identity and brand identity necessitates a novel form of organizational governance of identities outside the organization. As consumers actively interpret the signifying complexes of brands, coconstructing meaning through the act of consumption, the process of branding is necessarily partially autonomous of the organization. To steer this process, and manage the reception/reproduction of the brand, is the main function of brand management. For an organization promoting authenticity, this brand management function is partly dependent upon employees maintaining the integrity of the brand through their role as bearers of the brand. Our account of Ethico therefore looks 'inside' the organization to understand the parallel processes of internal and external branding, and analyses the ways 
in which the organization's ethical imperatives shaped both the labour process in the organization and employees' lives outside of work.

\section{Data analysis}

\section{Founding narrative and work/life message}

Ethico was founded as a mail order t-shirt design and sales company in 1995 by two life partners working and living in central London. Both had been working in corporate advertising for around 15 years. By their account, they began to question whether living and working in this way was how they wanted to spend their lives. This founding 'escape' narrative is prominent on Ethico's website and is also expressed in the brand identity, appearing regularly on t-shirts through slogans such as 'Big City Defector'. The company struggled in London for a few years until the founders decided to relocate to a rural location near where they had grown up. That location now features as a central element of the brand, representing an authenticity and modesty of aspiration that is contrasted with the arrogant gigantism of the big city/big corporation.

The idea of size, expressed in the company's parodic claim to be the 'third largest' clothing manufacturer in the small town where they are based, operates as a surrogate for authenticity and trustworthiness, opposed to an image of instrumental, bureaucratic, bigbusiness impersonality. This is often combined in the brand with tales of fallibility and adversity. The founding narrative emphasises how many times the founders had to remortgage their home, putting family life at risk for the company they believe in. Similarly the idea that Ethico is not perfect but is doing the best possible, for example by revealing mistakes that they have made or acknowledging imperfections in their environmental credentials whilst promising to try harder in the future, represents the authentic, fallible, human side of the organization.

The founders of Ethico always wanted it to be 'more than just a company'. A handwritten slogan on a wall inside the building exhorts employees: 'Let's use this little company of ours to make people think'. Ethico promotes moderate success, small size, and the desire to 'do something different, be noticed and have a voice'. One interviewee noted that they wanted the company to be 'big in importance and exposure, to show that there's a different way to do business'. An anti-business anti-success ethic is found in 
many of the interview transcripts, summed up by one of the founders arguing that 'we've never really had that strong business side', emphasising that they follow instinct, do their best, behave irrationally, and take risks. At the heart of this is a tension: the idea that work should not take over life but that, if organized correctly, work and business can actively contribute to life and make the world a better place. The implication is that 'mainstream' urban life and large organizations encourage the wrong kind of work and work ethic, and that Ethico offers a real alternative.

This alternative is clearly expressed through t-shirt slogans. As one of the sales team explained, Ethico consider t-shirts to be a medium as much as a functional item of clothing; the company has recently finished building an ecologically low-impact printing workshop where t-shirts could be printed in small batches at short notice to respond quickly to, and comment upon, current events. The idea that messages are the main products, and that the material product bearing the message is secondary, emphasizes the significance of immaterial labour. Two t-shirts stand out as representing the core of the brand identity. An early t-shirt, discussed on the company website, carried the phrase 'work hard, canoe home'. There are numerous references on Ethico blogs to how employees commute by environmentally friendly methods and the belief that, with care and effort, going to work can be a pleasure rather than a chore, that work can be balanced with leisure and a light ecological footprint. Customers are encouraged to think that ecological responsibility, hard work and a good life can be mutually supportive rather than contradictory. A variant on this message is found on a more recent t-shirt featuring a pseudo-Soviet Realist representation of manual workers, complete with sickles, hammers and stars, coupled with the injunction to 'live lightly' and 'labour sincerely'. Again, the idea of living 'lightly' (in an environmentally sustainable way) is combined with hard work and authenticity, themes that we found repeated to us time and again during data collection. This theme of balancing work and life surfaced most clearly in the three examples discussed next.

\section{Balancing Work and Life 1 - Too nice to work day}

Shortly before our visit to Ethico, managers decided to reward staff for a particularly good sales period. All employees were issued with a 'Too nice to work day' voucher, to cash in whenever they chose to take a day off. The image on the voucher was the company logo superimposed over a picture of a large wave, evoking the surfing and 
coastal orientation of the brand. Most people we spoke to mentioned these vouchers as evidence of enlightened employment practices at Ethico; however no one had yet used one. The vouchers had been issued some months before, yet everyone we interviewed still had theirs in a drawer.

About a month later we heard more about the 'Too nice to work day' scheme when one of the employees - Gael - used hers to take a day off to go sea kayaking. Gael worked in clothing design and quality control and was a keen kayaker. In interview she told of the factors that first attracted her to working at Ethico, primarily the brand commitment to such sports. Of interest here is that when Gael used the voucher to take a day off she wrote about it on the company blog, including a photograph of her on the sea. Without suggesting that her desire to go kayaking was in any way inauthentic, what this episode suggests is that she was aware that the 'Too nice to work day' voucher was simultaneously an internal reward and a branding opportunity. This is reinforced by the appearance of the voucher scheme on the company website when it was set up.

Given that the brand is the main product of the company, and that Gael's time off work kayaking was deliberately inscribed into the brand narrative, this raises the question of whether this leisure activity should also be considered 'work', given that it is productive of economic value. Arvidsson (2006: 10) suggests that in contemporary labour processes the distinction between work and life, or between productive labour and unproductive communication and consumption, 'becomes but a matter of function (whether a particular activity is positioned as labour or not)'. For employees like Gael, working in a brand-based organization, the labour process of brand production extends into life and leisure so that on a day when it is 'too nice to work', labour continues, and contributes more to the organizational production of value the more voluntary and authentic it is.

\section{Balancing work and life 2 - Surf's up}

This dynamic whereby employees' lives are incorporated into the brand narrative for economic gain is made even more explicit in our second example. Mark is a surfing enthusiast who joined the company early in its history. As for Gael, Ethico's stated commitment to sports was something that attracted him to the company. Recruiting people like Mark was common practice, facilitating the construction of the brand as 'real' or authentic. As one of the founders explained in interview: 
'...lots of people who work here are into either the ethical, green, environmental thing or the sport thing, or both... and it's quite nice to have people who come in and do the job but who've also got another dimension to them so they can bring something to the brand as well, you know... Jim can blog honestly and truthfully about mountain biking... Mark has days off to go surfing and thinks we don't know... Business brains would go 'hold on a minute, that guy's just snuck off and I'm sure he's always away on a Friday'... but if you marked your staff out of $10 \ldots$ they bring more than one thing to their job. Maybe his phone manner might not be brilliant and he'd score 5 there, but his actual brand story will score 10 because we can write about it in the catalogue.'

Indeed, Mark had appeared in a catalogue feature that playfully correlated height of surf with his days off sick. This article established a 'laid back' approach to absence, particularly when it was to engage in the sports activities that support Ethico's brand and function as a surrogate for its counter-cultural commitments and authenticity. As with Gael, an escape from work was tolerated, even encouraged and celebrated, insofar as it contributed to the value of the brand.

As well as the founders recognising this brand value, and recruiting for it, Mark himself saw his surfing as essential to establishing the company's credentials. In quantitative terms, however, a balance between work and leisure was not easy to maintain:

'I've surfed the least working at Ethico, but that's just the nature of the beast really because we had to build it up and stuff but it is getting a lot better... it's laziness on my part and not getting up early enough, but it's an hour's drive over [to the beach] and by the time I get home it's about $7 \ldots$ A couple of times last year I stayed at the beach and went surfing at $6 \mathrm{am}$ then went into work. Its kind of knackering but it's worth it if it's good... It's down to me to make it fit in rather than Ethico.' (Mark)

In Mark's example, we find that while the brand image is one of an enlightened employer with work and life combined into a seamless whole, the reality may be one of hard work and sacrificing 'life' to put in the hours necessary to run a successful business. These pressures to work hard were not experienced as resulting from the demands of management or the company itself, however, but from the 'nature of the beast': naturalised competitive capitalism. Crucially this meant that responsibility for finding 
time to 'live', given that the demands of work were determined by a faceless 'beast', were internalised and failures to achieve balance attributed to individual laziness.

Sometimes Mark did make time to surf, and felt legitimated in doing so when it contributed to work and to Ethico's authenticity. Although sport features in the Ethico brand as a good in itself, and something that employees intrinsically value, for it to be integrated with work it had to contribute to growing the business and developing the brand narrative. As Mark put it:

'We're trying to get people more involved in doing that kind of thing [sports] as it's kind of fallen by the wayside for a couple of years just because there was too much work, but... when I go out to the shops and stuff, especially down in Cornwall, then I certainly take my surfboard there and go surfing. With the shops that's part of it... to meet people and show that you are doing what you say you're doing rather than just writing a load of rubbish.'

As with Gael's use of her voucher to go kayaking and then blog about it, Mark's surfing serves to establish the authenticity and credibility of the brand. In contrast to the ideal of a balanced work and life, however, autonomous leisure and life was quantitatively squeezed by the demands of formally contracted work, and qualitatively transformed by its positioning as immaterial labour for the brand. This incorporation of the self into brand as a means of establishing authenticity is especially clear in our final example.

\section{Balancing work and life 3 - Scars vs. tattoos}

Richard is a skater who works in design and has primary responsibility for the catalogue. In interview he was adamant that Ethico was a sports clothing manufacturer, despite relaxed styling and a focus on street sports and surfing fashion. Richard contributed to this idea in a blog entry entitled 'Tattoos can be bought, scars have to be earned'. The text is accompanied by a photo of Richard's arm, covered in scars, and lists the skateboarding injuries he has sustained over the years. He argues that his scars were earned rather than bought, to emphasise (paradoxically) to Ethico customers that by buying the company's products they are accessing an authenticity that can only be earned. The labour capitalised in creating this brand authenticity was Richard's autonomously chosen, subjectively motivated leisure activity of skating, but this is retrospectively recast into the function of productive labour through its incorporation into the brand story. 
It is also worth noting here that this blog post came after widespread internet circulation of stories of Nike managers having the corporate 'swoosh' logo tattooed into their skin. Richard's story therefore serves to challenge the idea that Nike managers are committed to their brand. More significantly though it is also an inversion whereby the body and its life history became inscribed into the brand, rather than the brand inscribing the body.

\section{Inside/Outside - Branded Lives}

Our focus so far has been on the relationship between employees' life activities and the labour of brand construction. We have drawn out the significance of employees' recreational labour, an aspect of 'life', for the production of brand and the establishment of its authenticity for consumers. Internal branding, close to the management of organizational culture, is also significant in this case, as Mark noted when discussing the philosophy and articles featured in the catalogues:

'... quite a lot of it is for us, to tell us how to work and live our lives and stuff. So it's not just saying 'We're this great company, we're doing all these things.' It's for us really to tell us how we should be doing things.'

The ethical, values-driven foundation and brand proposition of Ethico therefore has an internal disciplinary dimension. For core employees, who were mostly attracted to the company because of its distinctive values, Ethico was experienced as a community. It offered a sense of belonging and shared values, values partly autonomously codetermined by members of the organization. As suggested by studies of community and teamworking as forms of concertive control, however, this created a normative imperative to act in accordance with these values (Barker, 1999; Land, 2010). The slogans, articles and philosophies found in the catalogues and blogs, and on the walls of the offices and warehouse, advised people how to work and how to live their lives. Like Richard, some of the members bore the scars of this lifestyle to prove their commitment and authenticity. Paralleling the production of the brand, this 'internal' branding did not stop at the end of the working day or on leaving the building, but transgressed the work/life boundary and contributed to the qualitative transformation of work, life, and their interactions.

\section{Discussion: Branding and the imperative to authenticity}


Our data analysis suggests that dominant conceptions of work/life balance and boundary maintenance need to be developed to acknowledge the more complex interplay between 'life' activities notionally located outside both formal, paid-employment and unpaid, domestic labour. Responding to calls to explore the relations between work and leisure/recreation (Lewis, 2003; Ransome, 2007), our study of work and life in a brandbased organization suggests the need to also locate these activities and their interactions in a broader political-economic context. Specifically, the case study highlights the economic significance of employees' leisure activities in creating exchange value through the co-production of meaning and the 'signifying complex' of the brand (Arvidsson, 2006). Ethico does not manufacture any material commodities. Most of the design work and all of the production, with the exception of designing and applying some t-shirt slogans, was outsourced. The company manufactured the Ethico brand by producing catalogues, a website, and other marketing communications. In order to establish the authenticity of the brand, this immaterial labour of brand management drew upon the recreational activities of employees. This inscription of employees' lives into the brand created the economic value of the company's products, situating their 'lives' as a form of productive labour or 'work'.

The accounts of Gael, Mark, Richard, and the company's founders, all suggest that employees and managers were aware of the centrality of employees' identities and lives to the integrity of the brand. Understood from a political-economic perspective, this recognition that value is produced by employees' activities outside the workplace reframes leisure as labour, life as work. Whilst most work/life balance literature focuses on the quantitative extension of work into spheres of activity defined as 'life', our analysis suggests that the changing articulations of work and life should also be understood qualitatively. As the immaterial labour of branding becomes increasingly central to the production of economic value, the conception of 'work', understood as value productive activity, has to be extended into areas that, whilst spatially and temporally 'life', are qualitatively transformed into labour by their relations to value production.

In this sense, our analysis of Ethico reinforces Arvidsson's (2006) understanding of brand management as the governance of communicative labour. Whereas Arvidsson tends to focus on the production of semi-autonomous consumption outside of the 
organization, however, the work of Lewis (2003), Ransome (2007) and Fincham (2008) draws our attention to employees' articulations of work and life, thereby bringing the focus of analysis back to the labour process. As the Ethico case suggests, for employees in brand-based companies, the labour process does not stop at the factory gate or office door. It spills over into life, but this is not a simple quantitative extension of an unchanged activity 'work'. Rather, activities previously coded as 'life' become work through their connection to the brand.

This connection is itself part of, and contingent upon, the employment relationship. As with other aspects of the labour process, this form of 'work' is carefully managed. As Mark's discussion of the function of the brand suggests, 'quite a lot of it is for us, to tell us how to work and live our lives'. This internal branding functions as a form of identity management that extends beyond the workplace to govern the performance of labourunderstood as value productive activity - in work and life. In contrast to the optimism of Arvidsson (2006), whose analysis focuses mainly on consumers, our study of employees in a brand-based organization suggests a deepening and intensification of control that transgresses work/life boundaries.

This is not a straightforward, quantitative increase of 'control' however. As Arvidsson's (2007) study of the launch party for a car demonstrates, the labour of those paid by an organization to produce brand value necessarily remains relatively autonomous. Without that autonomy, the values at the heart of the brand proposition ring hollow and authenticity is compromised. At Ethico, if the employees had not genuinely subscribed to the values articulated in the brand, the external branding could well have failed and the internal branding would have been ineffective, at least in shaping 'life' activities. The internal branding that governed employees' labour at work and play could only function because it associated the brand and employment with Ethico employees' autonomous, independent lifestyles and ethical values, including those of independence and autonomy. Through being able to co-construct and articulate the company's brand values, employees ensured both brand authenticity and their own buy-in. After all, these were their values and the brand was just reminding them of how they thought they should be living. This accords with Ransome's (2007) definition of recreational labour in terms of inherent motivations and subjective desire. If such activities became entirely instrumentalised and subordinated to extrinsic motivation, they would simply become 
work; however it is precisely their continued status as 'life' that makes them effective as a form of labour and enables them to contribute to the production of value by establishing brand authenticity.

\section{Conclusion}

Rather than rejecting the work/life boundary altogether, as some have done (DyerWitheford, 1999; Fincham, 2008), we are suggesting a more nuanced appreciation of its articulation and of the interdependence of work and life as they are qualitatively transformed by the recomposition of post-modern, communicative capitalism. Illustrating this, we discovered that around two weeks after we visited Ethico, one of the key employees whose life provides material for brand construction posted a blog entry on the organizational website about our research. A photograph of both of us in the workspace was accompanied by a short text that provided playful commentary on our research interests, and assured readers that we would find that Ethico is a good place to work. Through researching organizational incorporation of employee lives, we found our own selves and work incorporated as a support for Ethico's branding.

However not all visitors or employees provide valuable material. As writers in the labour process tradition note, changes in work and organization associated with postmodernisation can be overstated in their significance. Analysis often neglects the fact that for the majority of employees the realities of work have not changed much in recent years (Thompson and Warhurst, 1998; Thompson, 2005). It is clear that one of the limitations of our analysis here is our focus on a small core of employees who were recruited specifically for their affinity with the company's brand values. Another group had a very different story to tell about work/life balance and identity. The four men working in the warehouse downstairs, and the three women who staff the phones and take orders upstairs in the main office, worked to set hours except in very busy periods when they were expected to work paid overtime. They were all local and defined work as a means of paying for life. None spoke of working at Ethico because of sports or environmental interests. Our analysis in this paper concentrates on the interplay of work, life, and identity for those involved in constructing the Ethico brand - those at more senior levels in the company, employed on salaried contracts, taken on in part to enable brand construction - but this is not the whole story of brand-based capitalism. An even 
fuller account of work for Ethico would also, for example, include the labour processes of those workers in China and Turkey who manufacture the garments that carry the brand, and the couriers who deliver their orders, as well as the non-core employees within the company.

This limitation should not, however, lead us to overlook the fact that for some, particularly those interpolated by discourses of professional identity or ethics, 'life' and its relationship to 'work' have been qualitatively transformed by changes in the nature of labour, the composition of capital, and the incorporation of substantive ethical values into brand propositions. The full implications of these changes for control and resistance in the labour process, for our understanding of work/life balance, and in their broader significance for the sociology of work, are open to further research. The case presented here suggests one avenue of analysis that such research might pursue. 


\section{Acknowledgements}

We would like to thank the people who contributed to the data collection process at

Ethico, especially the then media officer who worked to organize access to the company workspace. This paper has benefitted from presentation at the European Academy of Management conference in Liverpool, and at Nottingham Business School. We would also like to thank Steffen Böhm (University of Essex) for a close reading and encouragement. Finally the editorial team and reviewers provided valuable guidance, challenges and suggestions. 


\section{References}

Arvidsson, A. (2006) Brands: Meaning and V alue in Media Culture. Abingdon: Routledge. Barker, J. (1999) The Discipline of Teamwork: Participation and Concertive Control. Thousand Oaks, CA: Sage.

Böhm, S. and C. Land (2009) 'The Value of Knowledge: Five Hypotheses', in D. Jemielniak and J. Kociatkiewicz (eds.) Handbook of Research on Knowledge-Intensive Organizations. Information Science Reference.

Carducci, V. (2006) 'Culture Jamming: A Sociological Perspective', Journal of Consumer Culture, 6(1): 116-138.

Clutterbuck, D. (2003) Managing Work-Life Balance: A Guide for HR in Achieving Organisational and Individual Change. London: CIPD.

Dalla Costa, M. and S. James (1975) The Power of Women and the Subversion of the Community. Berlin: Falling Wall Press.

Dyer-Witheford, N. (1999) Cyber-Marx: Cycles and Circuits of Struggle in High-Technology Capitalism. Urbana: University of Illinois Press.

Edwards, P. and J. Wajcman (2005) The Politics of Working Life. Oxford: Oxford University Press.

Fincham, B. (2008) 'Balance is Everything: Bicycle Messengers, Work and Leisure', Sociology, 42(4): 618-634.

Flyvbjerg, B. (2006) 'Five misunderstandings about case study research', Qualitative Inquiry, 12(2): 219-245.

Glucksmann, M. (2000) Cottons and Casuals: The Gendered Organisation of Labour in Time and Space. London: Routledge.

Gregory, A. and Milner, S. (2009) 'Work-Life Balance: A Matter of Choice?’, Gender, Work and Organization, 16(1): 1-13.

Hall, S. (1980) 'Encoding/Decoding', in S. Hall, D. Hobson, A. Lowe and P. Willis (eds) Culture, Media, Language. London: Hutchinson.

Hardt, M. and Negri, A. (2000) Empire. Cambridge, MA: Harvard University Press. Harold, C. (2004) 'Pranking Rhetoric: “Culture Jamming” as Media Activism', Critical Studies in Media Communication, 21(3): 189-211.

Heelas, P. \& Woodhead, L. (2007) The Spiritual Revolution: Why Religion is Giving Way to Spirituality. Oxford: Blackwell.

Klein, N. (2000) No Logo. London: Flamingo. 
Land, C. (2010) 'Community', in P. Hancock and A. Spicer (eds.) Understanding Corporate Life. London: Sage.

Lau, K. (2000) New Age Capitalism: Making Money East of Eden. Philadelphia: University of Pennsylvania Press.

Lazzarato, M. (1997) 'Immaterial Labor', in P. Virno and M. Hardt (eds.) Radical Thought in Italy: A Potential Politics. Minneapolis: University of Minnesota Press.

Lewis, S. (2003) 'The Integration of Paid Work and the Rest of Life. Is Post-industrial Work the New Leisure?‘, Leisure Studies, 22(4): 343-345.

Lewis, S. and Cooper, C. (2005) Work-Life Integration: Case Studies of Organisational Change. Chichester: Wiley.

Lewis, S., R. Gambles and R. Rapoport (2007) 'The Constraints of the 'Work-Life Balance' Approach: An International Perspective', International Journal of Human Resource Management, 18(3): 360-373.

Marx, K. (1976) Capital, Volume 1. London: Penguin.

McKie, L., Gregory, S. and Bowlby, S. (2002) 'Shadow Times: The Temporal and Spatial Frameworks and Experiences of Caring and Working', Sociology, 36(4): 897-924.

Nadeem, S. and Metcalf, H. (2007) 'Work-Life Policies in Great Britain: What Works, Where and How?', London: Department for Business Enterprise and Regulatory Reform. Available at http://www.berr.gov.uk/files/file40753.pdf (accessed 28/4/09). Negri, A. (1991) Marx Beyond Marx: Lessons from the Grundrisse. New York: Autonomedia. Poulter and Land (2008) 'Preparing to work: dramaturgy, cynicism and normative 'remote' control in the socialization of graduate recruits in management consulting', Culture and Organization, 14(1): 65-78.

Quinn, J.B. (1992) Intelligent Enterprise. New York: The Free Press.

Ransome, A. (2007) 'Conceptualizing Boundaries Between 'Life' and 'Work”, International Journal of Human Resource Management, 18(3): 374-386.

Seymour, J. (2007) 'Treating the Hotel like a Home: The Contribution of Studying the Single Location Home/Workplace', Sociology, 41(6): 1097-1114.

Smithson, J. and E. Stokoe (2005) 'Discourses of Work-Life Balance: Negotiating 'Genderblind' Terms in Organizations', Gender, Work and Organization, 12(2): 147-168. Stake, R. (2005) 'Qualitative Case Studies', in N. Denzin and Y. Lincoln (eds) The Sage Handbook of Qualitative Research (third edition). London: Sage.

Taylor, S. (forthcoming) 'Gendering the homeopathic milieu: A critical realist analysis of homeopathic work', Gender, Work and Organization. 
Thompson, P. (2005) 'Foundation and Empire: A Critique of Hardt and Negri', Capital and Class, 86: 73-98.

Thompson, P. and C. Warhurst (1998) Workplaces of the Future. Basingstoke: Macmillan. Wajcman, J. (2008) 'Intimate Connections: The Impact of the Mobile Phone on Work Life Boundaries', in G. Goggin and L. Hjorth (eds) Mobile Technologies: From Telecommunications to Media. London: Routledge.

Wajcman, J., Bittman, M. and Brown, J. (2008) 'Families without Borders: Mobile Phones, Connectedness, and Work-Home Divisions', Sociology, 42(4): 635-652.

Warhurst, C., D.R. Eikhof and A. Haunschild (2008) Work Less, Live More? Critical Analysis of the Work-Life Boundary. Basingstoke: Palgrave.

Watts, J. (2009) “Allowed into a 'Man's World' Meanings of Work-Life Balance: Perspectives of Women Civil Engineers as 'Minority’ Workers in Construction', Gender, Work and Organization, 16(1): 37-57.

Wright, S. (2002) Storming Heaven: Class Composition and Struggle in Italian Autonomist Marxism. London: Pluto. 


\section{Chris Land}

Is a Lecturer in Management at the University of Essex. His research interests include the organization of intentional communities, representations of organization in fiction, and the work of visual artists. He has previously worked at the universities of Warwick and Leicester.

Address: Essex Business School, University of Essex, Colchester CO4 3SQ, UK. Email: cland@essex.ac.uk

\section{Scott Taylor}

Is senior lecturer in the Centre for Leadership Studies, University of Exeter Business School. His main research interest is work and workplaces that are conditioned by religious and spiritual belief systems. He has researched and lectured at Manchester Metropolitan, Open, Birmingham, and Essex universities.

Address: Centre for Leadership Studies, University of Exeter Business School, University of Exeter, EX4 4PU, UK.

Email: scott.taylor@exeter.ac.uk

\footnotetext{
${ }^{1}$ As one of the reviewers pointed out, there are embedded gender and class dynamics that run through our analysis in this paper. We are very conscious of the significance of these and other aspects of social situatedness, empirically and theoretically. However, here we are presenting a reading of existing analyses of work/life balance through a particular theoretical lens, focusing on the experiences of those employees whose lives are appropriated to construct brand value. As such, we limit our analysis both empirically and theoretically but, as we note in the conclusions, these limitations could be addressed through further research or analysis.
} 